\title{
Makna Spiritual dan Unsur Stilistika dalam Mantra Ngeroras Adat Hindu Bali di Desa Werdhi Agung
}

\author{
Dessy Najenia Suwija, Kamajaya Al Katuuk, Viktory Nicodemus J. Rotty \\ Jurusan Pendidikan Bahasa dan Sastra Indonesia, Fakultas Bahasa dan Seni, Universitas Negeri \\ Manado \\ dessynajeniasuwija@gmail.com,kmjkatuuk30@gmail.com,viktoryrotty@unima.ac.id
}

\begin{abstract}
Abstrak. Penelitian ini bertujuan untuk mengungkapkan makna Spiritual dan Unsur Stilistika yang terdapat dalam mantra Ngeroras. Metode yang digunakan yakni metode deskriptif kualitatif dan dengan teknik pengumpulan data observasi dan wawancara, sedangkan dengan teknik analisis data berupa pengumpulan data, reduksi data, penyajian data, verivikasi dan penegasan kesimpulan. Berdasarkan analisis data didapatkan bahwa, makna spiritual yang ada dalam upacara negeroras meliputi : 1) makna dari mantra Amet Toya Hening (mengambil air jernih) adalah diharapkan dengan air yang disiramkan ke tempat atma atau roh yang dingeroras akaan bersih dan suci. 2) makna spiritual dari Mapinton atau Mapajati diharapkan apabila upacara ngeroras di laksanakan dapat berlangsung dengan baik dan roh leluhur yang dingeroras mendapatkan kedamain, kebebasan, ketenang, dan kesempurnaan. 3) makna spiritual dari ngilenin padudusan diharapkan dewa surya yang agung dengan kilauan yang merah dapat hadir dalam acara ngeroras dan memberi kesemarakan kedalam acara ngeroras tersebut. 4) makna spiritual dari pitra puja diharapkan atma atau roh leluhur dapat mencapai surga akhirat tanpa penderitaan. 5) makna spiritual dari pitra puja diharapkan atma suci mendapatkan tempat di Moksa dan tak terlahir kembali atau mendapat keabadian di akhirat tanpa ada siksaan. 6) makna spiritual dari pitra puja diharapkan atma suci mendapatkan ketenangan yang abadi. 7) makna spiritual pitra puja diharapkan atma suci mendapatkan kebahagian abadi di akhirat. 8) makna spiritual pitra puja diharapkan atma suci mendapatkan pengampunan dari hyang widhi.9) makna spiritual pralina maknanya agar atma suci mencapai moksa dan menyatu dengan ida sang hyang widhi wase dan tanpa suka duka. 10) makna spiritual nganyud sekah diharapkan atma setelah kematian akan tetap mengingan menyebut om dan ingat kepada ida sang hyang widhi wase dengan kekuatan dan keabadiannya serta mengingan bahwa karma phala selalu mengikuti hingga di akhirat nanti. Sedangkan unsur stilistika dalam mantra ngeroras yaitu: repitisi, tautotes, asonansi, aliterasi, hiperbola, pararima, dan anaphora.
\end{abstract}

Kata Kunci: Makna Spiritual, Unsur Stilistika, Mantra Ngeroras Adat Bali

\section{PENDAHULUAN}

Bali masih melestarikan tradisi yang diwariskan secara turun-temurun meskipun berada dalam perantauan. Dimana Sebagian masyarakat Suku Bali melakukan transmigrasi kebeberapa daerah di Indonesia dan salah satunya adalah Sulawesi Utara. Suku Bali datang ke Sulawesi Utara membawa beragam wujud kebudayaan, tradisis dan adat istiadat. Meskipun masyarakat suku Bali yang telah berbaur dengan masyarakat suku Bolaang Mongondow namun kebudayaan dan kebiasaan mereka tidak pernah hilang.

Sebagian besar dari masyarakat Suku Bali yang beragama Hindu tinggal di lingkungan komunitas mereka sendiri di desa Werdhi Agung kecamatan Dumoga Tengah kabupaten Bolaang Mongondow. Salah satu contohnya, masyarakat yang tinggal di desa tersebut mayoritas masyarakat Suku Bali beragama Hindu. Hindu Bali berbeda dengan Hindu Jawa dan Hindi India. Hindu Bali memiliki karakteristik, kebudayaan dan tradisi tersendiri yang tidak dimiliki oleh Hindu Jawa dan Hindu India. Hindu Bali memiliki nilai-nilai Agama yang universal, seperti religius, etika, dan keseimbanngan Nilainilai tersebut selalu dijadikan pedoman dan di jalankan oleh masyarakat Suku Bali yang beragama Hindu dalam kehidupan sehari-hari. Selain nilai-nilai agama, Hindu Bali memiliki tiga kerangka dasar yang harus dipahami oleh umat Hindu Bali. Pertama Tattwa adalah cara kita melaksanakan ajaran 
agama dengan mendalami pengetahuan dan filsafat agama. yang Keddua susila yaitu cara kita beragama dengan mengendalikan pikiran, perkataan dan perbuatan sehari-hari agar sesuai dengan kaidah-kaidah agama. dan yang Ketiga adalah upacara, upacara adalah suatu kegiata keagamaan dalam bentuk yadnya atau kegiatan-kegiatan suci.

Kebudayaan Hindu Bali dapat dilihat dari banyaknya upacara-upacara suci yang dilaksanakan dan menjadi ciri khas dari Hindu Bali. Masyarakat Hindu Bali memiliki berbagai macam bentuk upacara keagamaan, salah satu upacara keagaam adalah Panca Yadnya. Panca Yadnya berasal dari dua kata yaitu Panca yang artinya lima dan Yadnya artinya karya suci. Jadi Panca Yadnya artinya lima jenis karya suci yang dilaksanakan umat Hindu Bali untuk mencapai kesempuraan hidup. Adapun bagiabagian dari Panca Yadnya yaitu Dewa Yadnya, Bhuta Yadnya, Manuse Yadnya, Rsi Yadnya dan Pitra Yadnya, dari salah satu yadnya tersebut ada salah satu yang membahas tentang kematian dalam Hindu Bali yaitu Pitra Yadnya, Pitra Yadnya adalah karya suci atau persembahan suci kepada roh-roh atau leluhur.

( Nala, 2009, 115 ) upacara-upacara yang dilaksanakan dalam upacara Pitra yadnya adalah sawa wedana (pembakaran jenasah), asti wedana (ngaben/nganyud) dan yang terakhir atma wedana (ngeroras) sebagai rangkaian dari upacara kematian adat Bali. Salah satu upacara yang paling penting dari kematian adat Bali adalah Ngaben dan Ngeroras yang dalam pelaksanaanya memiliki tujuan dan makna masing-masing.

Tradisi ngeroras mempunyai makna dan fungsi, yaitu proses pengembalian manusia kepada penciptanya dan untuk menghormati para leluhur atau orang yang telah meninggal. Upacara ngeroras juga bertujuan membersihkan (mamarisuda) keluarga mendiang, rumah dan segala alat yang dulunya dipakai dalam membakar jenasah. Tujuannya adalah untuk mengakhiri cuntaka (kotor) secara kagamaan (Nala, 2009, 135).

Jadi dalam penelitian ini penulis ingin mengangkat salah satu tradisi bali yaitu tradisi ngeroras, upacara ngeroras di tunjukan untuk menghormati para leluhur atau orang-orang yang telah meninggal dunia. Ngeroras sendiri berasal dari kata $R O$ yang artinya dua dan Ras yang bermakna pisah sehingga kalau dijabarkan secara elaboratif, ngeroras berarti pisa dua kaki. upacara ngeroras dimaknai sebagai pemanggilan roh yang sudah di aben untuk disucikan kembali didalam ritual upakara ngeroras dimana sesudah upacara ini seluruh roh yang di aben diangkat untuk bersatu dengan Hyang Widi.

Tepatnya di desa Werdhi Agung, kecamatan Dumoga Tengah, provinsi Sulawesi Utara yang penduduknya mayoritas bersuku Bali, karena masyarakat yang tingggal di desa Werdhi Agung bertransmigrasi dari bali. Di desa ini masih sangat memegang erat tradisi adat Bali yaitu salah satunya upacra ngeroras. Disetiap rangkaian upacara ngeroras adat Bali identik dengan mantra-mantra atau doa, jadi peneliti ingin meneliti dalam doa atau mantra-mantra ngeroras apakah memiliki makna spiritual dan unsur stlistika?

Contoh mantra ngeroras

Om svargantu pitaro

Deva, svargantu pitara

Ganam, svargantu pitara

Sarvaya, nama svada.

"om hyang widhi semoga atmanya mendapat tempat disurga, semoga semua atma suci mendapat tempat disurga, sembah hamba hanya kepada hyang widhi dan hormat hamba kepada semua atma yang suci."

Om moksantu pitaro

Devah, moksantu pitara

Ganam, moksantu pitarah

Sarvaya, nama svada.

"om hyang widhi semoga atmanya mencapai moksa, semoga semua atma suci mencapai moksa, sembah hamba hanyalah kepada hyang widhi dan hormat hamba kepada semua atma suci."

\section{METODE}

Metode yang digunakan dalam penelitian ini adalah metode deskriptif, yaitu suatu metode yang berusaha menggambarkan suatu masalah yang menjadi objek dalam penelitian. Penelitian deskriptif 
tertuju pada pemecahan masalah yang ada pada masa sekarang, karena banyak penelitian maka metode deskriptif merupakan istilah yang umum yang mencakup berbagai teknik deskriptif antara lain metode dengan teknik wawancara,dan teknik observasi (Nawawi, 1993, 63).

Teknik pengumpulan data dalam penelitian ini yakni: 1. Pengumpulkan data Pengumpulkan data adalah merangkum,dan memilih data-data yang penting atau pokok. Dengan pengumpulkan data tersebut akan memberi gambaran jelas dan mempermudah peneliti. 2. Reduksi data Diartikan sebagai proses pemilihan, pemusatan perhatian pada penyederhanaan dan informasi data kasa yang munculdari catatancatatan tertuli di lapangan. Reduksi di lakukan sejak pengumpulan data dmulai dengan membuat ringkasan, mengkode, menelusuri tema, membuat gugus-gugus, menulis memo dan sebagainya dengan maksud menyisihkan data/informasi yang tidak relevan. 3. Penyajian data Selanjutnya peneliti akan menggambarkan, menjelaskan atau menafsirkan dan menyampaikan dalam bentuk narasi maupun dalam bentuk persentasi yang dapat di pahami. 4. Verifikasi dan penegasan kesimpulan Merupakan kegiatan akhir dari pengumpulan data. Penarikan kesimpulan berupa kegiatan interpretasi, yaitu menemukan makna data yang telah disajikan

\section{HASIL DAN PEMBAHASAN}

\section{A. Mantra Ngeroras}

1. Ngangget Don Bingin, yaitu upacara memetik daun beringin (kalpataru/kalpavriksa) untuk dipergunakan sebagai bahan puspasarira (symbol badan roh) yang nantinya dirangkai sedemikian rupa seperti sebuah tumpeng (dibungkus kain putih), dilengkapi dengan prerai (ukiran/lukisan wajah manusia, laki/perempuan) dan dihiasi dengan bunga ratna. Upacara ini berupa prosesi (mapeed) menuju pohon beringin diawali dengan tedung agung, mamas, bandrang dan lain-lainnya. Sebagai alas daun yang dipetik adalah tikar kalasa yang di atasnya ditempatkan kain putih sebagai pembungkus daun be ringin tersebut.

Interpretasi :(Ngangget Don Bingin yaitu upacara memetik daun beringin, adapun pohon beringin yang bisa digunakan untuk sekah atau puspasarira merupakan pohon beringin yang sudah diupacarai secara khusus. Makna dalam pengambilan daun beringin ini iyalah sebagai bentuk dari atma yang akan dingerorasin karna saat pelaksanaan upacara ini tidak ada jenazah sehingga perlu di buatkan symbol-simbol seperti ini.)

2. Ngajum, setelah daun beringin tiba di tenpat upacara, maka untuk masing-masing perwujudan roh, dipilih sebanyak 108 lembar, ditusukan dirangkai sedemikian rupa kemudian disebut Sekah. Jumlah Sekah sebanyak roh yang akan diupacarakan, di samping jumlah tersebut, dibuat juga untuk Lingga atau Sangge. Setelah Sekah dihiasi seperti tubuh manusia dengan busana selengkapnya (berwarna putih), dilakukan upacara Ngajum, yaitu mensthanakan roh pada Sekah tersebut, sekaligus ditempatkan di panggung upacara yang disebut Payajnan (tempat upacara yang khusus untuk itu terbuat dari batang pinag yang sudah dihaluskan).

Interpretasi : (Ngajum sekah maknanya di mana dalam pelaksanaan upacara harus memiliki perwujudan, dan sekah ini lah sebagai perwujudan dari atma tersebut Dimana daun beringi yang telah di ambil dipilih sebanyak 108 lembar dan dibentuk sedemikian rupa.)

3. Amet Toya Hening, adalah Rangkaian upacara selanjutnya dapat dilakukan pagi hari menjelang hari $\mathrm{H}$ berupa prosesi (mapeed) mengambil air jernih (toya hening) sebagai bahan utama air suci (Tirtha) bagi pandita atau dwijati yang akan memimpin upacara yajna Mamukur tersebut. Toya hening tersebut ditempatkan di bale Pamujaan (Pawedaan) di depan panggung Payajnan.

Interpretasi :( Amet Toya Hening (mengambil air jernih) maknanya dimana dalam pelaksanaan upacara ngeroras diperlukan air suci (tirtha) yang digunakan untuk menyucikan atma.)

\section{Mantra : om mang parama ciwa amertha ya namah swaha \\ Artinya : om hyang widhi parama siwa dalam aksara mang pelebur mala, menganugrahkan amerta}

Makna Spiritual : makna dari mantra ini merupakan diharapkan dengan air yang disiramkan ke tempaat atma atau roh yang dingeroras akaan bersih dan suci. 
4. Mapinton atau Mapajati, adalah upacara ini berupa prosesi mapeed bagi (roh yang diupacarakan) untuk mempermaklulmkan kepada para dewata yang bersthana pada pura-pura terdekat, utamanya pura untuk pemujaan leluhur (Kawitan).

Interpretasi : (Mapinton atau Mapajati maknanya di mana diberitahukan atma yang diupacarakan akan melaksanakan upacara ngeroras kepada dewa yang ada di pura terdekat).

Mantra : om dewa pitara sarwa pariwara guna swaha, harsayah sawa pujanam prasidantu suka krstam, om atasabai, om wasinanaya mang ung, mokshantu, swargantu, suniyantu, ang ksama sampurne ya namah swaha.

Artinya : oh hyang widhi, yang menguasai roh leluhur kami, hamba memuja-mu agar segala sesuatunya berjalan baik, semoga roh leluhur kami mencapai kebebasan, kedamaian, ketenangan, dan kesempurnaan.

Makna Spiritual : diharapkan apabila upacara ngeroras di laksanakan dapat berlangsung dengan baik dan roh leluhur yang dingeroras mendapatkan kedamain, kebebasan, ketenangn, dan kesempurnaan.

5. Mapradaksina, upacara ini sering disebut Mapurwadaksina, yaitu prosesi mapeed bagi puspasarira yang dipangku atau dijunjung oleh anak cucu keturunannya, memakai bhusana serba putih, dilakukan pada hari " $\mathrm{H}$ ", setelah upacara Mapinton, mengelilingi panggung Payajnan sebanyak 3 kali dari arah selatan kea rah timur mengikuti jejak lembu putih yang dituntun oleh gembalanya, di atas hamparan kain putih, dilakukan secara khusuk, diiringi gamelan gambang, saron atau slonding, gong gede, kidung kakawin, pembacaan parwa (Mahabharata) dan Putrupasaji (bisa oleh Walaka senior).

Interpretasi: (Mapradaksina makna upacara ini merupakan atma yang di junjung oleh anak cucunya dituntun untuk di sucikan).

6. Puncak Upacara, bersamaan dengan upacara Mapradaksina atau Mapurwadaksina seseorang atau beberapa pandita Sulinggih yang memimpin pelaksanaan upacara juga melakukan upacara:

a. Melaspas bukur atau madya atau padma anglayang, alat untuk mengusung puspasarira yang telah disucikan (di-pralina) berupa meru (beratap bertumpang) dihias dengan hiasan kertas emas, kemudian ditempatkan di dekat panggung Payajnan.

Interpretasi : (. Melaspas bukur atau madya atau Padma anglayang maknanya menyucikan alat atau tempat untuk atma yang telah disucikan).

b. Ngaliwet yaitu upacara menanak nasi sebagai saji tarpana (penek/pulung-pulung kecil) disebut panda, sebanyak 108 buah dipersembahkan kepada roh yang diupacarakan, disamping dipersembahkan kepada para dewata dan leluhur. Memasaknya dilakukan di depan Sanggar Tawang (depan panggung Paajnan) dipimpin oleh pandita. Beras yang dipersiapkan diatas nyiru berisi lukisan padma dan wijaksara (hurup suci) tertentu dituangi empehan (susu) dan madu (madhuparka).

Interpretasi : (Ngeliwet maknanya, memberikan makanan berupa nasi yang dibentuk bulat sebanyak 108 buah yang dicampur susu dan madu yang telah berisi lukisan huruf suci kepada atma, dewa dan leluhur yang hadir dlam upacara tersebut).

c. Ngenyitin Damar Kurung yang ditempatkan di sebelah panggung Payajnyan atau di pintu masuk areal upacara.

Interpretasi : (Ngenyiten damar kurung (menyalakan lampu terkurung/lampion) maknanya meberikan jalan kepada atma yang dingerorasin).

d. Ngilenan Padudusan yaitu melaksanakan upacara panyucian dutujukan kepada Sanggar Tawang (Sanggar Surya) untuk memohon perkenan para dewa/dewata turun menyaksikan dan menganugrahkan keberhasilan Yajna tersebut di panggung Payajnan untuk menyucikan roh-roh yang diupacarakan. 
Interpretasi : (Ngilenang Padudusan maknanya meminta agar dewa surya untuk memohon kedatangan para dewa/dewata dan menyaksikan keberhasilan upacara ngeroras dan menyucikan atma atu roh yang diupacarakan).

Mantra : om adityasya param jyoti, rakte-teje namo stute, sveta-pankaje-medhyaste, bhaskaraya namo stute.

Artinya : om hyang widhi, sebagai kemegahan yang agung putra aditi, ya dikau dengan kilauan yang merah, sembah kehadapan-mu dikau yang berdiri di tengah sekuntum teratai putih, sembah kehadapan-mu, penyebar kesemarakan.

Makna Spiritual : diharapkan dewa surya yang agung dengan kilauan yang merah dapat hadir dalam acara ngeroras dan memberi kesemarakan kedalam acara ngeroras tersebut

e. Muspa yaitu upacara persembahyangan yang didahului pemujaan kepada Sang Hyang Surya sebagai saksi agung alam semesta, kemudian kepada para dewata dan leluhur, serta sembah untuk pelepasan roh (Atma) dari ikatan Sukma Sarira yang diikuti oleh Sang Yajamana dan seluruh keluarga besarnya.

Interpretasi : (Muspa maknanya pemujaan kepada sang hyang surya sebagai saksi agung alam semesta, kemudian kepada para dewata dan leluhur yang hadir, serta menyembah untuk pelepasan roh atau atma dari ikatan sukma sarira atau badan halus dari duniawi).

Mantra pitra puja

\section{Mantra : Om svargantu pitaro}

\section{Deva, svargantu pitara}

Ganam, svargantu pitara

Sarvaya, nama svada.

Artinya :"om hyang widhi semoga atmanya mendapat tempat disurga, semoga semua atma suci mendapat tempat disurga, sembah hamba hanya kepada hyang widhi dan hormat hamba kepada semua atma yang suci."

Makna spiritual : diharapkan atma atau roh leluhur dapat mencapai surga akhirat tanpa penderitaan.

\section{Mantra : Om moksantu pitaro}

\section{Devah, moksantu pitara}

Ganam, moksantu pitarah

Sarvaya, nama svada.

Artinya :"om hyang widhi semoga atmanya mencapai moksa, semoga semua atma suci mencapai moksa, sembah hamba hanyalah kepada hyang widhi dan hormat hamba kepada semua atma suci."

Makna spiritual: diharapkan atma suci mendapatkan tempat di moksa dan tak terlahir kembali atau mendapat keabadian di akhirat tanpa ada siksaan.

\section{Mantra : Om sunyantu pitaro}

\section{Devah, sunyantu pitara}

Ganam, sunyantu pitarah

\section{Sarvaya, namah svada.}

Artinya :"om hyang widhi semoga atmanya mendapat ketenangan, semoga semua atma suci mendapat ketenangan, sembah hamba hanyalah kepada hyang widhi dan hormat hamba kepada semua atma suci."

Makna spiritual : diharapkan atma suci mendapatkan ketenangan yang abadi.

\section{Mantra : Om bhagyantu pitaro}

\section{Devah, bhagyantu pitara}




\section{Ganam, bhagyantu pitarah \\ Sarvaya, namah svada.}

Artinya :"om hyang widhi semoga atmanya mendapat kebahagiaan sejati, semoga semua atma suci dianugrahi kebahagiaan yang sejati, sembah hamba hanyalah kepada hyang widhi dan hormat hamba kepada atma suci."

Makna spiritual : diharapkan atma suci mendapatkan kebahagian abadi di akhirat.

\section{Mantra : Om ksamantu pitaro}

\section{Devah, ksamantu pitara}

Ganam, ksamantu pitarah

\section{Sarvaya, namah svada}

Artinya : "om hyang widhi semoga atmanya mendapat pengampunan, semoga semua atma suci dibebaskan segala dosanya, sembah hamba hanyalah kepada hyang widhi dan hormat hamba kepada semua atma suci."

Makna spiritual : diharapkan atma suci mendapatkan pengampunan dari hyang widhi.

f. Pralina yaitu upacara tahap akhir dilakukan oleh pandita (Sulinggih) sebagai symbol pelepasan Atma dari ikatan Sukma Sarira.

Interpretasi : (Pralina maknanya meberikan symbol kepada atma bahwa atma tersebut telah terlepas dari sukma sarira atau badan halus).

\section{Mantra : om svargantu, moksantu, sunyantu murcantu, om ksama sampurna ya namah svaha.}

Artinya : om sanghyang widhi wasa, semogalah arwahnya (almarhum) mencapai sorga, manunggal dengan-mu, mencapai keheningan, tempat tanpa suka duka.

Makna spiritual : maknanya agar atma suci mencapai moksa dan menyatu dengan ida sang hyang widhi wase dan tanpa suka duka.

g. Papendetan yaitu mempersembahkan tari-tarian, bahwa tapa pelepasan roh telah dilaksanakan, para leluhur sesaat lagi akan menuju alam sorga.

Interpretasi: (Papendetan maknanya menyatakan bahwa pelepasan roh telah dilaksanakan dan mempersilahkan para leluhur menuju surga).

h. Ngeseng Puspalingga yaitu membakar puspasarira (wujud roh) di atas dulang dari tanah liat atau dulang perak, dengan sarana sepit, penguyegan, balai gading dan lain-lain, dengan api pembakaran yang diberikan oleh pandita pemimpin upacara. Upacara ini sangat baik dilakukan pada dinihari saat dunia dan segala isinya dalam suasana hening guna mengkondisikan pelepasan Atma dari keduniawian.

Interpretasi : (Ngeseng Puspalingga maknanya mebersihkan roh dari keduniawian).

i. Sekah tunggal. Selesai upacara Ngeseng maka arang/abu dari puspasasrira dimasukkan de dalam degan (kelungah) kelapa gading dibungkus kain putih dan dihias dengan bunga harum selanjutnya aisthanakan di dalam bukur di atas padma anglayang atau dalam bokor perak diikuti dengan persembahyangan oleh keluarga.

Interpretasi : (sekah tunggal maknanya mengistirahatkan roh yang telah di sucikan dan terlepas dari duniawi).

j. Nganyut Sekah ke Segara. Upacara ini merupakan tahap terakhir dari upacara Mamukur, dapat dilakukan pagi hari selesai upacara Ngeseng Sekah disebut upacara Ngirim. Setelah tiba di tepi pantai, arang/abu yang ditempatkan didalam kelapa gading dikeluarkan dan ditebarkan di tepi pantai yang didahului dengan upacara persembahyangan sesajen kepada Sang Hyang Baruna, sebagai 
penguasa laut, sekaligus permohonan penyucian rethadap roh yang diupacarakan dan diakhiri dengan persembayhangan oleh keluarga.

Interpretasi : (Nganyut sekah ke segare maknanya mengirim roh dan menyucikan roh dengan menghanyutkan kesungai atau ke laut).

\section{Mantra : om vayur anilam amrtam athedam bhasmantam sariram, aum krato smara, klibe smara, krtam smara}

Artinya : wahai jiwa yang aktip, pada saat kematian, ingatlah menyebut om, ingatlah kepada tuhan yang maha esa, ingat kekuatan dan keabadian, ingatlah kepada karma phala dan sadarlah bahwa jiwa dan badan akhirnya hancur menjadi abu.

Makna spiritual : diharapkan atma setelah kematian akan tetap mengingan menyebut om dan ingat kepada ida sang hyang widhi wase dengan kekuatan dan keabadiannya serta mengingan bahwa karma phala selalu mengikuti hingga di akhirat nanti.

\section{B. Stilistika Mantra Ngeroras}

Mantra dipandang sebagai bidang sastra, kebahasaan dan kebudayaan. Mantra tidak hanya dapat mengungkap kepercayaan dan religi tetapi eksistensinya merupakan struktur verbal sastra lama yang dapat mengungkapkan beberapa hal seperti: ciri-ciri estetik yang meliputi betuk komposisi verbal, gaya, pilihan kata, serta pemanfaatan bunyi bahasa untuk mencapai efek tertentu.

Dalam penelitian ini ada sepuluh mantra yang di gunakan saat ngeroras dan lima diantaranya termasuk dalam stilistika mantra. Mantra-mantra ini memiliki keindahan karena di dalamnya terdapat beberapa gaya bahasa, seperti repetisi, tautotes, asonansi, aliterasi, anafora, hiperbola, pararima.

Repetisi atau pengulanga bunyi, suku kata, atau bagian lain dari kalimat yang dianggap penting untuk memberi tekanan dalam sebuah konteks yang sesuai, seperti yang terdapat pada kata svargantu pitara sebagai contoh:
Om svargantu pitaro
Deva, svargantu pitara
Ganam, svargantu pitara

Tautotes merupakan pengulangansebuah kata berkali-kalidalam sebuah konstruksi, seperti pada kata :

Om moksantu pitaro

Deva, moksantu pitara

Ganam, moksantu pitarah

Asonansi merupakan pengulanga huruf vocal yang sama. Seperti pada mantra:

Deva, ksamantu pitara

Ganam, ksamantu pitarah

Sarvaya, namah swada

Aliterasi yaitu pengulangan bunyi konsonan, seperti pada mantra:

Deva, bhagyantu pitara

Ganam, bhagyantu pitarah

Yang terjadi pengulangan bunyi konsonan /bh/ dan /p/

Hiperbola yaitu melukiskan suatu secara berlebih-lebihan seperti pada mantra:

Om adityasya param jyoti, rakte-teje namo stute

Yang artinya: om hyang widhi, sebagai kemegahan yang agung putra aditi

Pararima atau pengulangan bunyi konsonan awal dan akhir seperti yang terdapat pada mantra:

Bhasmantam sariram

Anaphora yaitu pengulangan kata atau frasa dalam satu kalimat, dimana kata yang diulangi tersebut adalah kata awal kalimat yang di ulangi atau ditulis kembali di tengah dan di akhir kalimat, seperti pada mantra: 
om dewa pitara sarwa pariwara guna swaha, harsayah sawa pujanam prasidantu suka krstam, om atasabai, om wasinanaya mang ung, mokshantu, swargantu, suniyantu, ang ksama sampurne ya namah swaha.

\section{KESIMPULAN}

Pada upacara Ngeroras terdapat 6 tahapan yang tidak bisa diubah dan diacak pada setiap tahapannya, jika tahapan yang terdapat pada Ngeroras maka maknanya itu tidak ada lagi. Dalam setiap tahapan Ngeroras memiliki mantra tersendiri yang bisa memimpin Upacara Ngeroras serta melantunkan mantranya adalah orang-oranng yang telah diberikan kepercayaan dan telah dilantik oleh pemerintah desa. Setiap mantra memiliki makna tersendiri dan memiliki fungsi tersendiri Mulai dari di tuntun kelak terlahir kembali menjadi pribadi yang lebih baik hingga di tuntun agar dapat menyatu dengan ida sang hyang widi wase. Cara mebacakan setiap mantra memiliki irama yang berbeda untuk menambah kesan spiritual yang mendalam.

\section{DAFTAR PUSTAKA}

I Gusti Nurah Nala. 2009, Sanatana Hindu Darma. Denpasar :Widya Darma Denpasar. Halaman 115

Nawawi, H. Hadari dan H. M. Martini Hadari. 1995. Instrumen Penelitian Bidang Sosial. Gadjah Mada University Press.Yogyakarta. 227 Halaman. 